\title{
Links between atmospheric blocking and North American winter cold spells in two generations of Canadian Earth System Model large ensembles
}

\author{
Dae Il Jeong ${ }^{1}$ (I) $\cdot$ Bin $\mathrm{Yu}^{1} \cdot$ Alex J. Cannon ${ }^{2}$
}

Received: 23 November 2020 / Accepted: 5 May 2021 / Published online: 13 May 2021

(c) Crown 2021

\begin{abstract}
Due to the significant negative consequences of winter cold extremes, there is need to better understand and simulate the mechanisms driving their occurrence. The impact of atmospheric blocking on winter cold spells over North America is investigated using ERA-Interim and NCEP-DOE-R2 reanalyses for 1981-2010. Initial-condition large-ensembles of two generations of Canadian Earth System Models (CanESM5 and its predecessor, CanESM2) are evaluated in terms of their ability to represent the blocking-cold spell linkage and the associated internal-variability. The reanalysis datasets show that 72 and 58\% of cold spells in southern and northern North America coincide with blocking occurring in the high-latitude Pacific-North America. Compared to the two reanalyses, CanESM2 and CanESM5 ensembles underestimate by 19.9 and $14.3 \%$ cold spell events coincident with blocking, due to significant under-representation of blocking frequency over the North Pacific ( -47.1 and $-29.0 \%)$, whereas biases in cold spell frequency are relatively small $(6.6$ and $-4.7 \%)$. In the reanalyses, regions with statistically significant above-normal cold spell frequency relative to climatology lie on the east and/or south flanks of blocking events, whereas those with below-normal frequency lie along the core or surrounding the blocking. The two ensembles reproduce the observed blocking-cold spell linkage over North America, despite underestimating the magnitude of blocking frequency. The two ensembles also reproduce the physical drivers that underpin the blocking-cold spell linkage. Spatial agreement with the reanalyses is found in the simulated patterns of temperature advection and surface heat flux forcing anomalies during blocking events. While CanESM5 shows an improved representation of the blocking climatology relative to CanESM2, both yield similar results in terms of the blocking-cold spell linkage and associated internal-variability.
\end{abstract}

Keywords Atmospheric blocking $\cdot$ Cold spell $\cdot$ GCM $\cdot$ Surface heat flux forcing $\cdot$ Temperature advection

\section{Introduction}

Winter cold extremes have adverse impacts on various human and natural systems (e.g., Roland and Matter 2013; Sheridan and Allen 2015). For example, the February 2012 cold spell in Eurasia led to the deaths of more than 600 people (WMO 2012), massive terrestrial bird mortality (Lormée et al. 2013), and severe damages in vineyards

Dae Il Jeong

daeil.jeong@canada.ca

1 Climate Research Division, Environment and Climate Change Canada, 4905 Dufferin Street, Toronto, ON M3H 5T4, Canada

2 Climate Research Division, Environment and Climate Change Canada, Victoria, BC V8W 2Y2, Canada
(Planchon et al. 2015). The cold wave and snowstorm that occurred over North America in early 2014 was blamed for economic losses in excess of 3 billion USD (LeComte 2015). Given the severity of the impacts of such events, it is of great importance to investigate the mechanisms that drive winter cold extremes.

Atmospheric blocking events are extratropical synopticscale anti-cyclonic systems that interrupt the predominant westerly flow and persist from a day up to a few weeks (Tibaldi and Molteni 1990; Trigo et al. 2004; Schwierz et al. 2004). Blocking events that occur in the North Pacific and North Atlantic in winter contribute to cold extremes over North America and Europe, respectively, by inducing northerly cold air advection (e.g., Buehler et al. 2011; Sillmann et al. 2011; Pfahl and Wernli 2012; Whan et al. 2016). The connection between blocking and cold extremes has often been investigated by statistical approaches, including 
correlation analysis (e.g., Sillmann et al. 2011), composite maps (e.g., Trigo et al. 2004), and extreme value analysis (e.g., Buehler et al. 2011; Whan et al. 2016).

Global climate models (GCMs) are the main tools used for climate prediction and projecting the future state of the climate system under different anthropogenic forcing scenarios. It is thus of utmost importance to evaluate the ability of GCMs to simulate the atmospheric circulation on various time scales. In particular, the linkage between blocking and temperature extremes is an important synoptic-scale feature that should be reproduced by GCMs. However, GCMs underestimate the frequency of blocking events, in particular minor underestimation of winter blocking frequency over the Pacific and Ural regions and significant underestimation of 10-50\% over the Euro-Atlantic region in the Coupled Model Intercomparison Project Phase 5 (CMIP5) GCMs (Davini and D'Andrea 2016; Woollings et al. 2018). Underestimation of winter blocking frequency is also reported from CMIP Phase 6 (CMIP6) GCMs, although they generally show an improved representation of blocking frequency and persistence in the Atlantic and Pacific relative to CMIP5 models (Davini and D'Andrea 2020; Schiemann et al. 2020).

Several studies have investigated the ability of climate models to represent the connection between blocking and temperature extremes over the Euro-Atlantic sector. For instance, Sillmann et al. (2011) reported that the linkage between eastern North Atlantic blocking and cold extremes in Europe represented by an atmosphere-ocean coupled GCM shows a reasonable agreement with observations. Masato et al. (2014) showed that the relationship between blocking and cold weather extremes is reproduced well over the Euro-Atlantic sector in four CMIP5 GCMs, despite their under-representation of the blocking frequency. Recently, Brunner et al. (2018) verified the performance of a 50-member ensemble of the second generation Canadian Earth System Model (CanESM2) in representing the relationships between blocking and cold extremes over the Euro-Atlantic sector. They also quantified the uncertainty in the relationship due to internal-variability using the large-ensemble. However, these relationships have been rarely studied over the Pacific-North American sector using climate model simulations. Whan et al. (2016) evaluated the ability of regional climate models (RCMs) to simulate the relationship between blocking and cold extremes over North America. They reported that the influence of blocking on cold extremes in the CanRCM4, CRCM5, HIRHARM5, and RCA4 RCMs is in good agreement with observations.

In this study, we investigate the connection between blocking and cold spells over the Pacific-North American sector in winter (December-February) based on ERAInterim reanalysis (Dee et al. 2011) and National Centers for Environmental Prediction-Department of Energy reanalysis 2 (NCEP-DOE-R2) (Kanamitsu et al. 2002) over the 1981-2010 period. We also evaluate the performance of the most recent Canadian Earth system model version 5 (CanESM5) and its previous version CanESM2 in reproducing the relationship between blocking and cold spells in comparison to the two reanalyses. The uncertainty due to internal-variability in the blocking-cold spell linkage is quantified using a 50-member ensemble of CanESM2 and 35-member ensemble of CanESM5, in which all variables are available for the assessment. The two ensembles are further investigated by assessing other synoptic-scale factors behind the blocking-cold spell link over North America, including air temperature advection at $850 \mathrm{hPa}, 500-1000$ $\mathrm{hPa}$ geopotential thickness, and surface heat flux forcing.

\section{Data and methods}

\subsection{Data}

The Canadian Centre for Climate Modelling and Analysis (CCCma) of Environment and Climate Change Canada (ECCC) developed the CanESM2 Earth system model that participated in CMIP5 and CanESM5 that contributes to CMIP6. CanESM2 includes coupled atmosphere, ocean, sea-ice, land, and terrestrial and ocean carbon cycle components (Arora et al. 2011). CanESM5, which is CCCma's latest coupled GCM, includes incremental updates to the atmosphere, land-surface, and terrestrial ecosystem models, in particular with the implementation of completely new components for the ocean, sea-ice, and marine ecosystems, as well as a new coupler (Swart et al. 2019). This study uses CanESM2 and CanESM5 simulations for the 1981-2010 period, which is also the period used by Swart et al. (2019) to compare CanESM5 with CanESM2 and observation datasets. CanESM5 simulations are based on historical CMIP6 emissions for the same period, while CanESM2 simulations use historical CMIP5 emissions up to 2005 and RCP8.5 emission scenario for 2006-2010. RCP8.5 is a highemission scenario that has closely matched recent emissions (Sanford et al. 2014). Within each of the two large ensembles, members of each model share the same forcings, differing only in initial conditions of the atmosphere and ocean state at the beginning of the historical simulation; therefore, each member has different realization of internal-variability under the given historical forcings (Fyfe et al. 2017). Minimum air temperature at 2-m, geopotential heights at 500, 850 , and $1000 \mathrm{hPa}, \mathrm{U}$ and $\mathrm{V}$ components of wind speed at $850 \mathrm{hPa}$, surface short and long wave solar radiations, and surface sensible and latent heat fluxes on daily timestep are used in this assessment. These variables are available from a 50-member ensemble of CanESM2 and, at the time of writing, a 35-member ensemble of CanESM5. The atmosphere component of CanESM2 and CanESM5 uses 
the spectral transform method with T63 resolution in the horizontal (approximately $2.8^{\circ}$ latitude $\times 2.8^{\circ}$ longitude) (Arora et al. 2011; Swart et al. 2019). For this assessment, all variables are interpolated to a grid spacing of $2.5^{\circ} \times$ $2.5^{\circ}$. The historical simulations are evaluated by comparing blocking events and their connection to cold spells over the Pacific-North American sector with NCEP-DOE-R2 and ERA-Interim reanalyses. NCEP-DOE-R2 provides pressure level variables at $2.5^{\circ}$ resolution but the other variables at $1.9^{\circ}$ resolution, which are interpolated to the $2.5^{\circ}$ grids in this study. All variables listed above are available for the ERA-Interim reanalysis at a horizontal-resolution of $0.75^{\circ}$. As our primary goal is the evaluation of CanESM2 and CanESM5 at $2.8^{\circ}$ resolution, reanalysis datasets at higher resolutions such as ERA5 at $0.28^{\circ}$ resolution (Hersbach et al. 2020) are not considered.

\subsection{Atmospheric blocking}

We employ a 2-dimensional blocking identification approach using meridional gradients of daily geopotential height fields at $500 \mathrm{hPa}$ (Z500) (Scherrer et al. 2006; Brunner et al. 2018; Woollings et al. 2018). At a longitude $\lambda$, meridional gradients of Z500 to the north $\left(\mathrm{GZ500}_{\mathrm{N}}\right)$ and to the south $\left(\mathrm{GZ500}_{\mathrm{S}}\right)$ are calculated for a given latitude $\phi$ :

$$
\begin{aligned}
& \operatorname{GZ500}_{\mathrm{N}}(\lambda, \varphi)=\frac{\mathrm{Z} 500(\lambda, \varphi+\Delta \varphi)-\operatorname{Z500}(\lambda, \varphi)}{\Delta \varphi} \\
& \operatorname{GZ500}_{\mathrm{S}}(\lambda, \varphi)=\frac{\mathrm{Z} 500(\lambda, \varphi)-\mathrm{Z} 500(\lambda, \varphi-\Delta \varphi)}{\Delta \varphi}
\end{aligned}
$$

where $50^{\circ} \mathrm{N}<\phi<75^{\circ} \mathrm{N}$ and $\Delta \phi=15^{\circ}$ latitude. An instantaneous blocking (IB) event is defined at the given grid point $(\lambda, \phi)$ when the two gradients simultaneously satisfy $\mathrm{GZF00}_{\mathrm{N}}<-10 \mathrm{gpm} /{ }^{\circ}$ and GZ500 $\mathrm{S}>0 \mathrm{gpm} /{ }^{\circ}$. Several studies (e.g., Davini and D'Andrea 2016; Li et al. 2017) have focused on the assessment of IB events; however, this study identifies extended blocking events from the two-dimensional IB field by further considering spatial magnitude and temporal persistence. A spatially extended IB event is identified contiguous IB extends over at least $15^{\circ}$ longitude to filter out spatially small events, while allowing for meridional movement within $\pm 5^{\circ}$ latitude. Finally, a blocking event is defined when the extended IB event stays within $10^{\circ}$ longitude for at least 5 consecutive days. In addition to the two reanalyses and the two ensembles, blocking frequency of up-scaled ERA-Interim at $2.5^{\circ}$ grids from $0.75^{\circ}$ resolution by interpolation is calculated to investigate the impact of grid-scale in the blocking detection.

Blocking events are further identified over five different longitude regions following Brunner et al. (2018) to explore the remote relationship between blocking location and North
American cold spells. The five regions are referred to as B1 $\left(210^{\circ} \mathrm{W}-180^{\circ} \mathrm{W}\right.$, including northeastern edge of Russia), B2 $\left(180^{\circ} \mathrm{W}-150^{\circ} \mathrm{W}\right.$, including western Alaska), B3 (150 ${ }^{\circ}$ $\mathrm{W}-120^{\circ} \mathrm{W}$, including eastern Alaska and western Canada), B4 $\left(120^{\circ} \mathrm{W}-90^{\circ} \mathrm{W}\right.$, including central Canada), and B5 $\left(90^{\circ}\right.$ $\mathrm{W}-60^{\circ} \mathrm{W}$, including eastern Canada). A blocking day in a blocking region is defined when more than half of the region (i.e., $15^{\circ}$ longitude inside the region) is covered by a blocking event. This identification is conducted based on daily dataset at annual timescale, and then blocking days are counted for each season. In addition to this, storm track activity, defined as the standard deviation of 2-8-day bandpass-filtered geopotential at 500-hPa (e.g., Yu et al. 2020), is calculated to investigate the relationship between eddy activity and blocking frequency over Pacific-North America.

Anomalies of other synoptic-scale atmospheric circulation factors, including temperature advection at $850 \mathrm{hPa}$, surface heat fluxes, and 1000-500 hPa geopotential thickness, are also evaluated during blocking episodes to better understand the physical insights behind the blocking-cold spell linkage. Horizontal temperature advection anomalies at $850 \mathrm{hPa}$ due to anomalous wind flows are calculated using $-\frac{\partial \overline{\mathrm{T}}}{\partial \mathrm{x}} \mathrm{u}^{\prime}-\frac{\partial \overline{\mathrm{T}}}{\partial \mathrm{y}} \mathrm{v}$ ' (Lehtonen and Karpechko 2016), where $\overline{\mathrm{T}}$ represents the climatological mean temperature, and $\mathrm{u}^{\prime}$ and $\mathrm{v}$ ' are the anomalous zonal and meridional wind components during blocking episodes relative to climatological daily means for the 1981-2010 period. The net of surface radiative and turbulent heat fluxes is calculated on daily timescale following $R_{S}+R_{L}-L E-H$ (Pettenuzzo et al. 2010), where the components represent shortwave solar radiation (downward), longwave solar radiation (downward), surface latent heat flux (upward), and surface sensible heat flux (upward), respectively. The net heat flux, therefore, approximately represents the summation of the ground heat flux and total heat energy stored in the surface layer for a day. Anomalies of the surface heat flux to climatological means are calculated during blocking days in the five regions.

\subsection{Winter cold spell}

A winter cold spell is defined as a period of at least three consecutive cold days with daily minimum temperatures below the threshold at a given grid point. The threshold is defined at each grid point for each day as the 10th percentile of daily minimum temperatures in the window of \pm 15 -days centered on the calendar day for the climatological 1981-2010 period (Fischer and Schär 2010; Brunner et al. 2018).

Based on blocking days identified in the regions B1-B5, unconditional probability of cold spell days and conditional probability of cold spell days during blocking are calculated for the 30-year period. The cold spell frequency anomaly 
$\left(\mathrm{P}_{\mathrm{ano}}\right)$, the ratio of the conditional probability to the unconditional probability, is then calculated for each grid point following:

$\mathrm{P}_{\mathrm{ano}}=\frac{\mathrm{N}_{\mathrm{CS} \mid \mathrm{B}} / \mathrm{N}_{\mathrm{B}}}{\mathrm{N}_{\mathrm{CS}} / \mathrm{N}}$

where $\mathrm{N}, \mathrm{N}_{\mathrm{CS}}, \mathrm{N}_{\mathrm{B}}$, and $\mathrm{N}_{\mathrm{CS} \mid \mathrm{B}}$ represent total number of days, number of cold spell days, number of blocking days, and number of cold spell days during blocking days, respectively (Brunner et al. 2018). Therefore, the value of $\mathrm{P}_{\mathrm{ano}}$ is larger than one when the conditional probability is larger than the unconditional probability, while it is close to one when cold spell occurrence is not relevant the blocking events. In addition, percentages of the number of cold spell events that overlap in time with any blocking days are calculated relative to total number of cold spell events over North America for each blocking region. We provide regional mean values over four North American regions defined as northwest (NW; $170^{\circ} \mathrm{W}-102^{\circ} \mathrm{W}$ and $\left.50^{\circ} \mathrm{N}-70^{\circ} \mathrm{N}\right)$, northeast (NE; $102^{\circ} \mathrm{W}-52^{\circ} \mathrm{W}$ and $50^{\circ} \mathrm{N}-70^{\circ} \mathrm{N}$ ), southwest (SW; $140^{\circ} \mathrm{W}-102^{\circ} \mathrm{W}$ and $30^{\circ} \mathrm{N}-50^{\circ} \mathrm{N}$ ), and southeast (SE; $102^{\circ}$ $\mathrm{W}-52^{\circ} \mathrm{W}$ and $30^{\circ} \mathrm{N}-50^{\circ} \mathrm{N}$ ) as shown in Fig. 3 .

Statistical significance of the linkage between blocking and the cold spell frequency anomaly is tested using a block bootstrap resampling approach that has been applied for serially correlated data (Efron and Tibshirani 1994). To account for correlation and persistence in blocking and cold spells, we use contiguous 15-day bootstrap resamples that could include a long blocking episode as well as a cold spell. The resampling is repeated 100 times from the series of blocking days and cold days for each blocking region at each North American land grid point. Statistical significance is defined when the 5-95th percentile range of the cold spell frequency anomaly quantified by the block bootstrap approach excludes one. The anomaly is therefore either statistically significantly higher or lower than climatology. Moreover, anomalies of surface heat fluxes and 1000-500 hPa geopotential thickness are also tested for statistical significance from zero using the bootstrap resampling approach. This significance test is applied for the reanalysis datasets and each ensemble member of CanESM2 and CanESM5.

\section{Results}

\subsection{Blocking frequency}

Observed blocking climatologies are defined for ERAInterim and NCEP-DOE-R2 data over the 1981-2010 period for all seasons in the five regions B1-B5. Results from CanESM2 and CanESM5 ensembles are then compared with the two observed climatologies (Fig. 1). The reanalyses and the two ensembles show an agreement in the spatial variability of blocking climatology. They display larger percentages of blocking days over the northeastern edge of Russia, northern Pacific, Alaska, and western Canada (i.e., regions B1-B3) as compared to central and western Canada (i.e., regions B4 and B5). This variability of the blocking climatology over the high-latitude Pacific-North America is consistent with previous findings (e.g., Whan et al. 2016; Woollings et al. 2018). Up-scaled $2.5^{\circ}$ ERA-Interim grids yield fewer blocking events than the original $0.75^{\circ}$ grids. This indicates that the detection of blocking events is highly dependent on the resolution of the geopotential height data when the 2-D meridional geopotential height gradient approach is applied. Interestingly, the up-scaled ERAInterim reanalysis and NCEP-DOE-R2 reanalysis, which are both at $2.5^{\circ}$ resolution, show an agreement in the blocking frequency. The two GCM ensembles, however, show a significant underestimation of blocking frequency in the regions $\mathrm{B} 1$ and B2 for all seasons and in the region B3 for spring to autumn; maximum blocking frequency amongst the ensemble members is smaller than the reanalyses. The negative bias of CanESM2 in the blocking climatology agrees with previous findings using CMIP5 GCMs (e.g., Anstey et al. 2013; Lee and Ahn 2017). The two ensembles show better agreement with the reanalyses in central and eastern Canada (i.e., regions B4 and B5), although the blocking frequency in these regions is smaller than in regions B1-B3. On average, CanESM5 performs better than CanESM2 in reproducing the blocking climatology, as CanESM5 and CanESM2 underestimate around 3 and 4 days of blocking, respectively, for each season when compared to NCEP-DOE-R2. Particularly for the regions B1 and B2 in winter, CanESM5 shows better agreement than CanESM2 with the reanalyses. Internal variability of each blocking climatology, as quantified by the spread in the two ensembles, is similar in CanESM2 and CanESM5.

The better performance of CanESM5 relative to CanESM2 is due to improved ability to reproduce largescale spatial patterns in the climate system, including 3-D distribution of northward winds, sea-level pressure, and sea-ice-covered regions (Swart et al. 2019). In particular, strong westerlies can suppress synoptic-scale eddy activity (e.g., Nakamura and Sampe 2002; Afargan and Kaspi 2017), which plays an important role in controlling the onset and persistence of blocking (Woollings et al. 2018). Therefore, positive biases in winter zonal winds and an associated stronger westerly jet in CanESM models relative to ERA5 (the successor to ERA-Interim) over the Northern Hemisphere (Swart et al, 2019) could contribute to the underestimation of winter blocking activity over the North Pacific region (B1 and B2). The relationship between eddy activity and blocking could partly explain the underestimated blocking frequency in the CanESM ensembles in summer, 


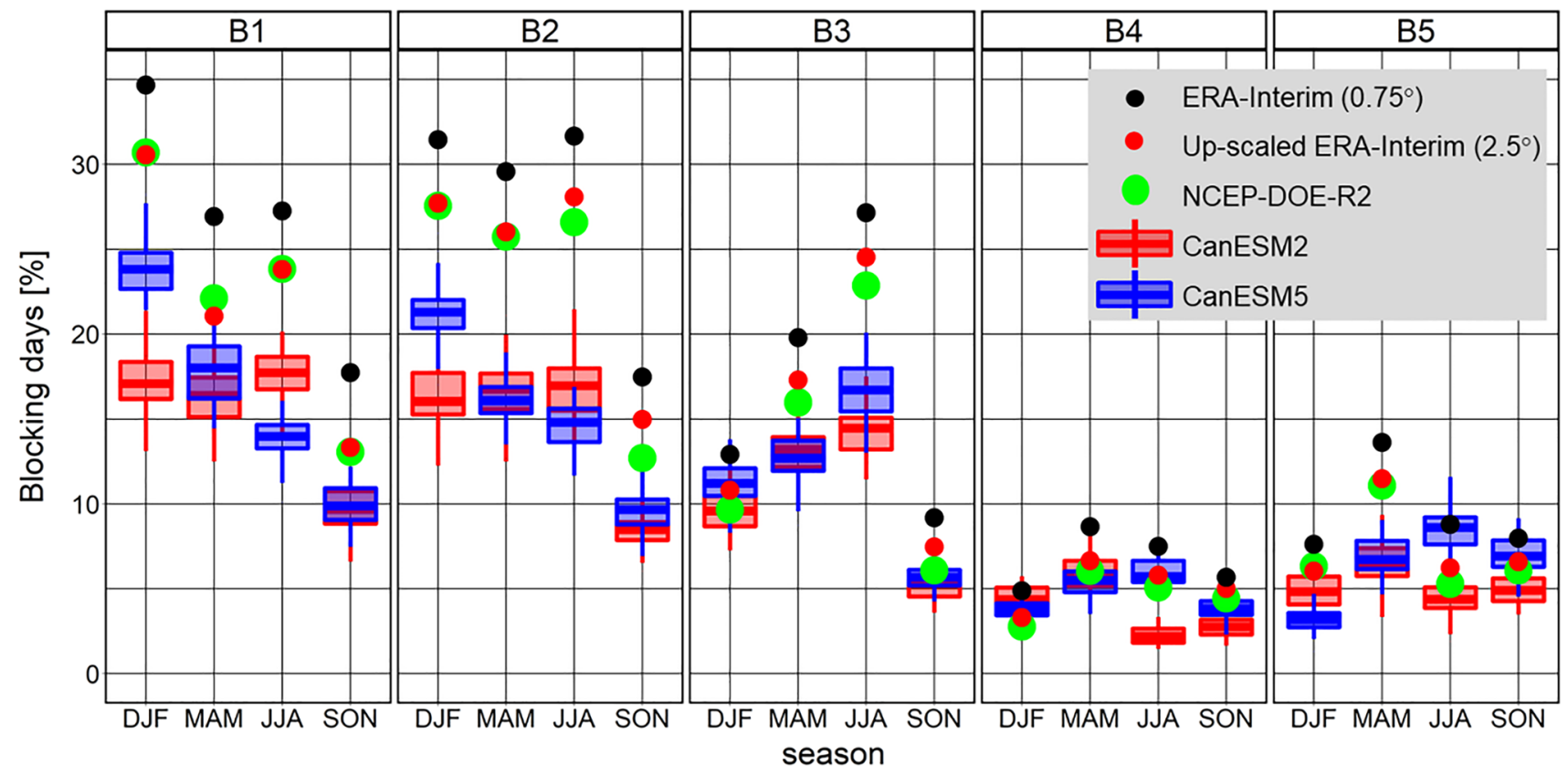

Fig. 1 Percentage of blocking days in five blocking regions of ERAInterim at $0.75^{\circ}$ (black dots), up-scaled ERA-Interim at $2.5^{\circ}$ (red dots), NCEP-DOE-R2 (green dots), CanESM2 ensemble (red boxplot), and CanESM5 ensemble (blue box-plot) for all seasons for the 1981-2010 period. The five blocking regions are located at high lati-

as CanESM storm track activity is underestimated relative to reanalyses in that season (Fig. 2). In winter, the CanESM5 ensemble shows better agreement with the reanalyses for tudes $\left(50^{\circ} \mathrm{N}-75^{\circ} \mathrm{N}\right)$ and referred to as $\mathrm{B} 1\left(150^{\circ} \mathrm{E}-180^{\circ} \mathrm{E}\right), \mathrm{B} 2\left(180^{\circ}\right.$ $\left.\mathrm{W}-150^{\circ} \mathrm{W}\right), \mathrm{B} 3\left(150^{\circ} \mathrm{W}-120^{\circ} \mathrm{W}\right), \mathrm{B} 4\left(120^{\circ} \mathrm{W}-90^{\circ} \mathrm{W}\right)$, and B5 $\left(90^{\circ} \mathrm{W}-60^{\circ} \mathrm{W}\right)$. DJF (December-February), MAM (March-May), JJA (June-August) and SON (September-November) represent the four seasons
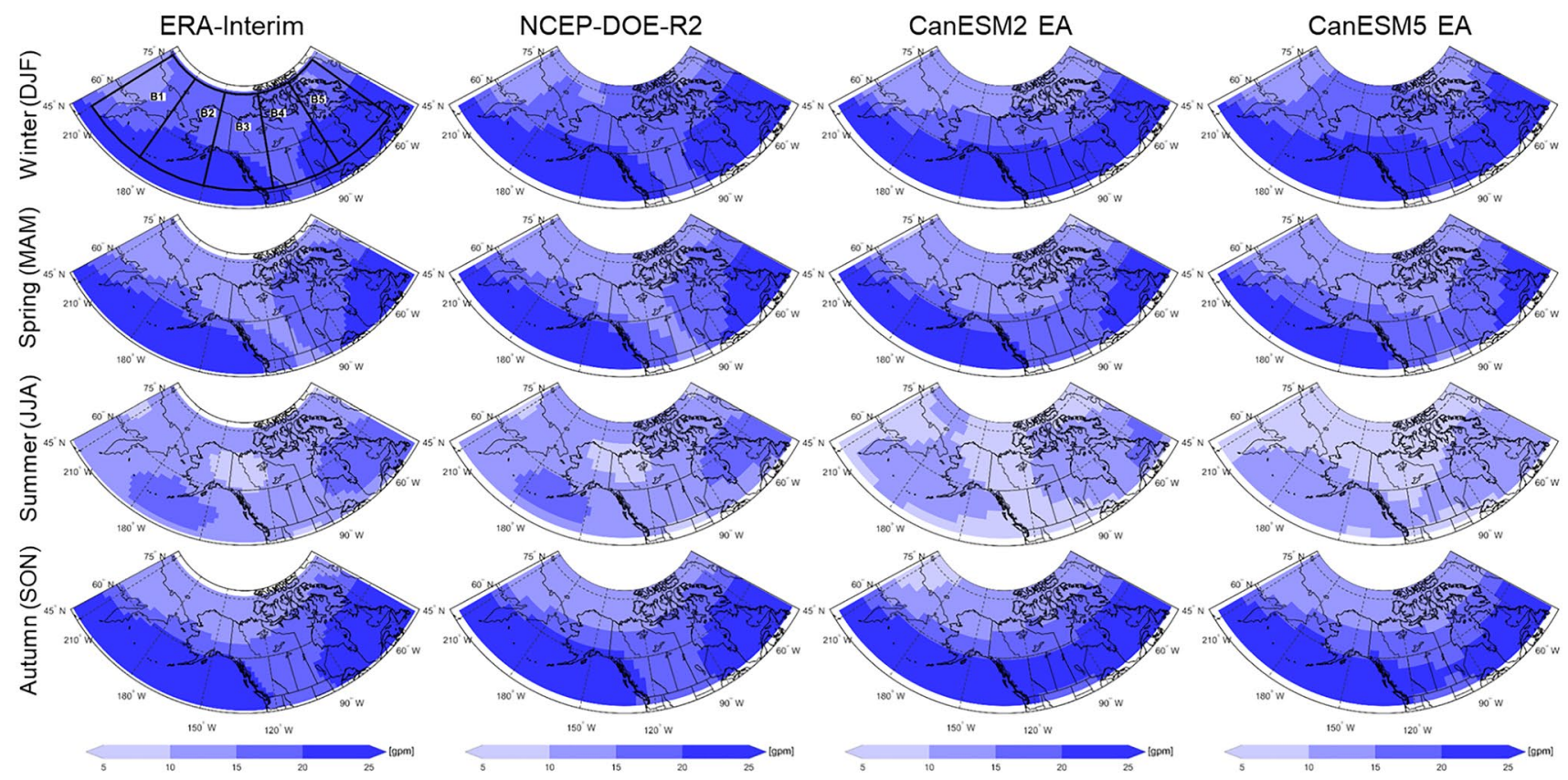

Fig. 2 Storm track activities (i.e., the standard deviation of the 2-8-day bandpass-filtered geopotential at 500-hPa) of ERA-Interim, NCEP-DOER2, and ensemble averages (EAs) of CanESM2 and CanESM5 for each season during the 1981-2010 period 
ensemble. Furthermore, Swart et al. (2019) found that positive biases of surface zonal winds of CanESM 5 at $30^{\circ} \mathrm{N}-60^{\circ}$ $\mathrm{N}$ are significantly improved over those in CanESM2.

\subsection{The linkage between blocking and winter cold spells}

Percentages of winter cold spell days of the two reanalyses and CanESM ensembles are compared in Fig. 3. Note that the percentage represents unconditional (climatological) probability of winter cold spell days in Eq. (2). The two reanalyses show a consistency in spatial patterns of the percentages with larger values over northwest (NW) and Great Plains but smaller values over northeast of North America (Fig. 3a). These spatial differences in cold spell frequency result from regionally different responses to the persistence of synoptic-scale circulation anomalies and land-atmosphere interactions (Grotjahn et al. 2016). CanESM2 and CanESM5 ensembles show an agreement with the reanalyses for the spatial patterns, with spatial correlation coefficients of 0.53 and 0.58 , respectively, compared to NCEP-DOE-R2. On average over North America, CanESM2 and CanESM5 show 0.1 day $(2 \%)$ and -0.4 day $(-8 \%)$ biases with respect to ERA-Interim and 0.5 day (11\%) and 0.002 day (0.4\%) biases with respect to NCEP-DOE-R2 for cold spell days per winter. Therefore, the two ensembles yield better performances for the unconditional probability of winter cold spells, compared to those for atmosphere blocking frequency shown in Fig. 1.

The connections between blocking events in the five regions B1-B5 and cold spell frequency anomalies over North America in winter are displayed using spatial maps in Fig. 4. Results are further summarized for the four regions of North America in Fig. 5a. Note that the frequency anomalies of the reanalyses and ensembles are relative to their unconditional probability of cold spells shown in Fig. 3. CanESM2 and CanESM5 ensembles show an agreement with the two reanalyses in the response of the cold spells over North America during blocking in high-latitude PacificNorth America. In particular, the two reanalyses and the two GCM ensembles show strong linkages between blocking and above-normal cold spell frequency at remote locations along the eastern and/or southern flanks of the blocking. These spatial teleconnections are in line with previous findings (e.g., Masato et al. 2014; Brunner et al. 2018). Meanwhile, the two reanalyses and the two ensembles yield a strong linkage between blocking and below-normal cold spell frequency at the core and surrounding areas of the blocking (i.e., where high-pressure anomalies and blocking-like circulation patterns coincide). However, a significant relationship between cold extremes and co-located blocking events may not be detectable for more extreme events and at higher confidence levels. For instance, Pfahl and Wernli (2012) found that the relationship between 1 st percentiles of 6-hourly minimum temperatures and co-located blocking events are not statistically significant at the $99 \%$ confidence level. (a)
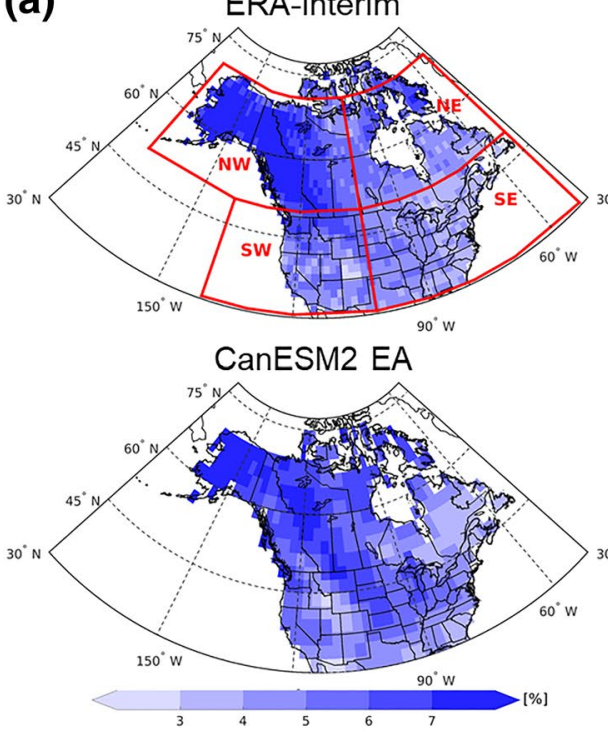
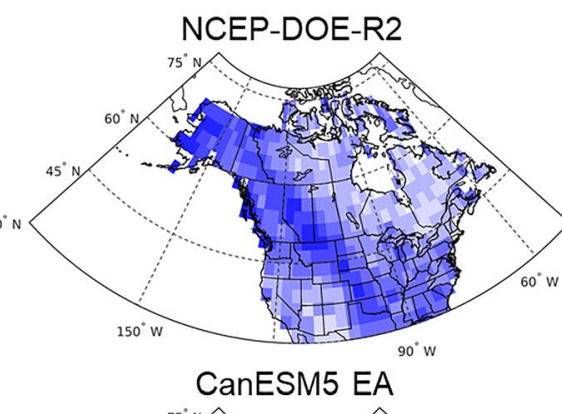

(b)

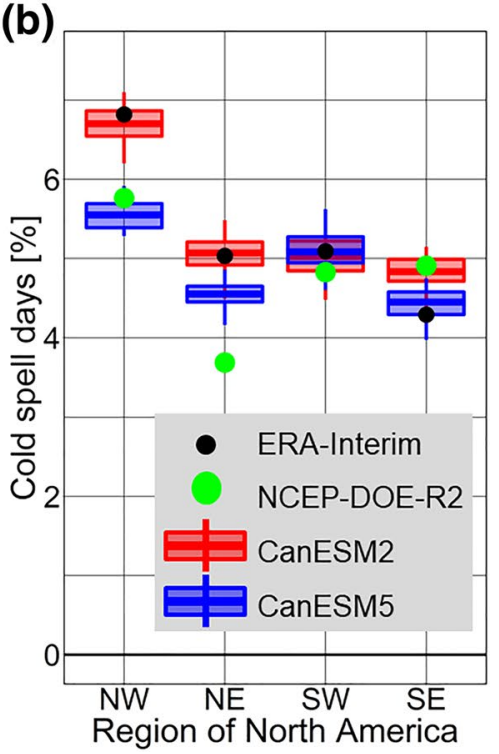

Fig. 3 a Percentage of cold spell days in winter (DJF) over North America for ERA-Interim, NCEP-DOE-R2, and ensemble averages (EAs) of CanESM2 and CanESM5 for the 1981-2010 period. b Regional averages of the percentage for ERA-Interim (black dots),
NCEP-DOE-R2 (green dots), CanESM2 ensemble (red box-plot), and CanESM5 ensemble (blue box-plot) on the four assessment regions of North America (NW, NE, SW, and SE) 


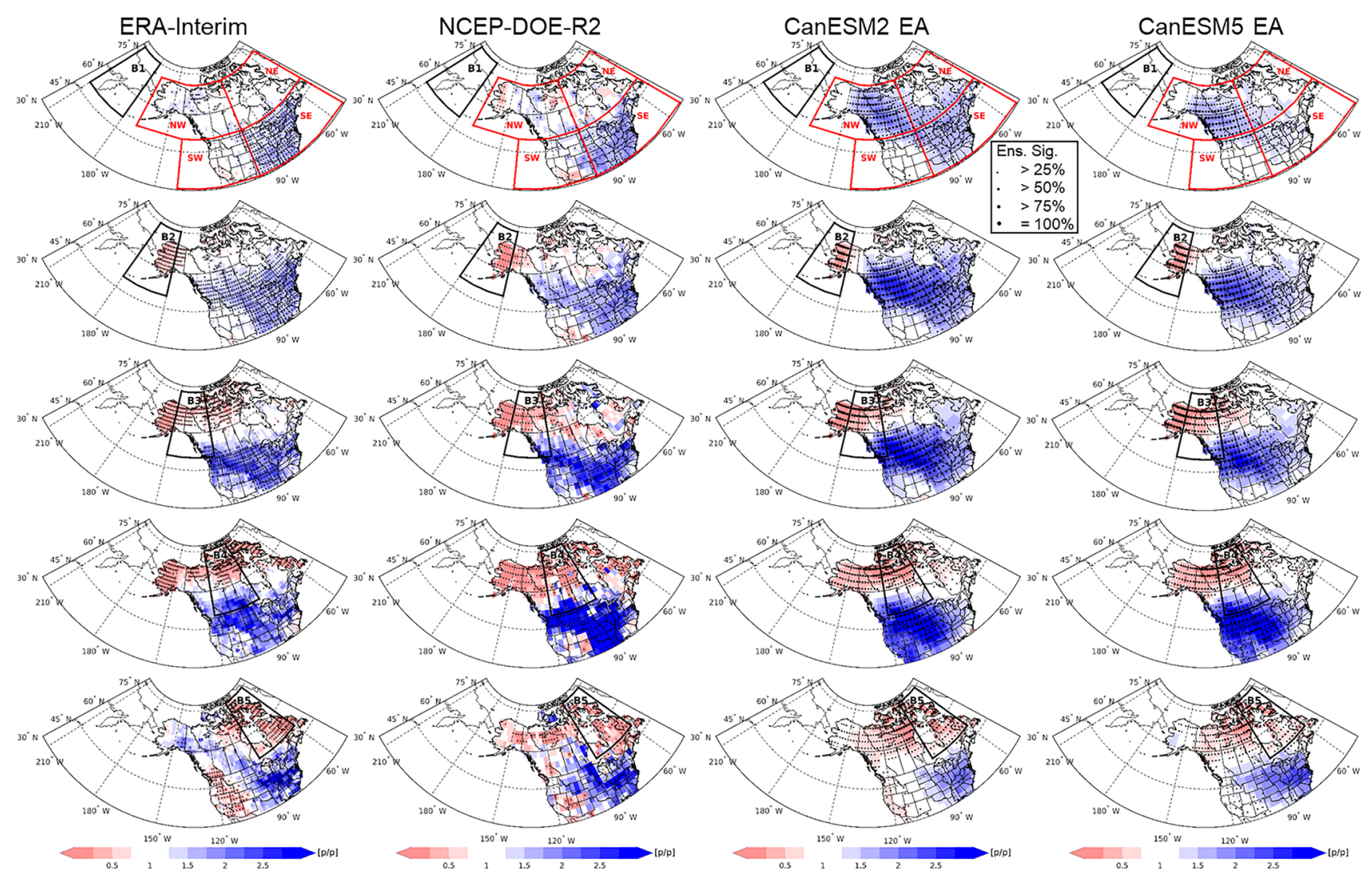

Fig. 4 Cold spell frequency anomaly during blocking in the five regions (B1-B5; black boxes) for ERA-Interim, NCEP-DOE-R2, and ensemble averages (EAs) of CanESM2 and CanESM5 in winter (DJF) for the 1981-2010 period. Black dots represent statistical significance at the $10 \%$ significant level (two-sided). The larger dot

CanESM2 and CanESM5 ensembles show remarkable regional-scale agreements and disagreements with the two reanalyses in the blocking-cold spell linkage. For instance, the two ensembles show an agreement with the reanalyses for the linkage between blocking in region B1 and insignificant cold spell frequency anomaly over the southwest North America as well as statistically significant abovenormal frequency over the southeast North America (first row in Fig. 4). However, the two ensembles yield a disagreement with the reanalyses in finding a link between blocking in the region B1 and cold spell frequency anomalies over northwest and northeast North America. In these regions, the two ensembles display a statistically significant abovenormal link while the two reanalyses show an insignificant connection, indicating the two ensembles could overestimate negative temperature advection during blocking in region $\mathrm{B} 1$ (detailed descriptions are given in the following section). Furthermore, while the two ensembles show good agreement with NCEP-DOE-R2, they sometimes display the opposite relationship with ERA-Interim. For instance, the two ensembles show statistically significant below-normal cold spell size for the CanESM2 and CanESM5 ensembles represents the larger number of ensemble members yield statistical significance (percentages of the number are defined in the legend). NW (northwest), NE (northeast), SW (southwest, and SE (southeast) in the first row represent the four assessment regions of North America

frequency whereas ERA-Interim yields some above-normal frequency over northwest North America for the blocking in the region B5 (fifth row in Fig. 4). Nevertheless, the two ensembles and the two reanalyses show spatially better agreement for the link between blocking in the regions B2-B5 and cold spells over North America. These spatial agreements and disagreements are also found in the regional averages for the four regions of North America (Fig. 5a). The two ensembles yield larger uncertainty in the connections between cold spell frequency anomalies and blocking in the regions B3-B5, compared to those in the regions B1 and B2. This indicates the two ensembles have smaller internal-variability for more frequent cases of synoptic-scale atmospheric circulation patterns associated with blocking occurring from the northeastern Russia to western Alaska, compared to the cases in the western to eastern Canada as shown in Fig. 1.

It is also important to evaluate how many cold spells occurring over North America are connected with atmospheric blocking occurring over the high-latitude PacificNorth America that should be reproduced by the CanESM2 


\section{(a) Cold spell frequency anomaly}

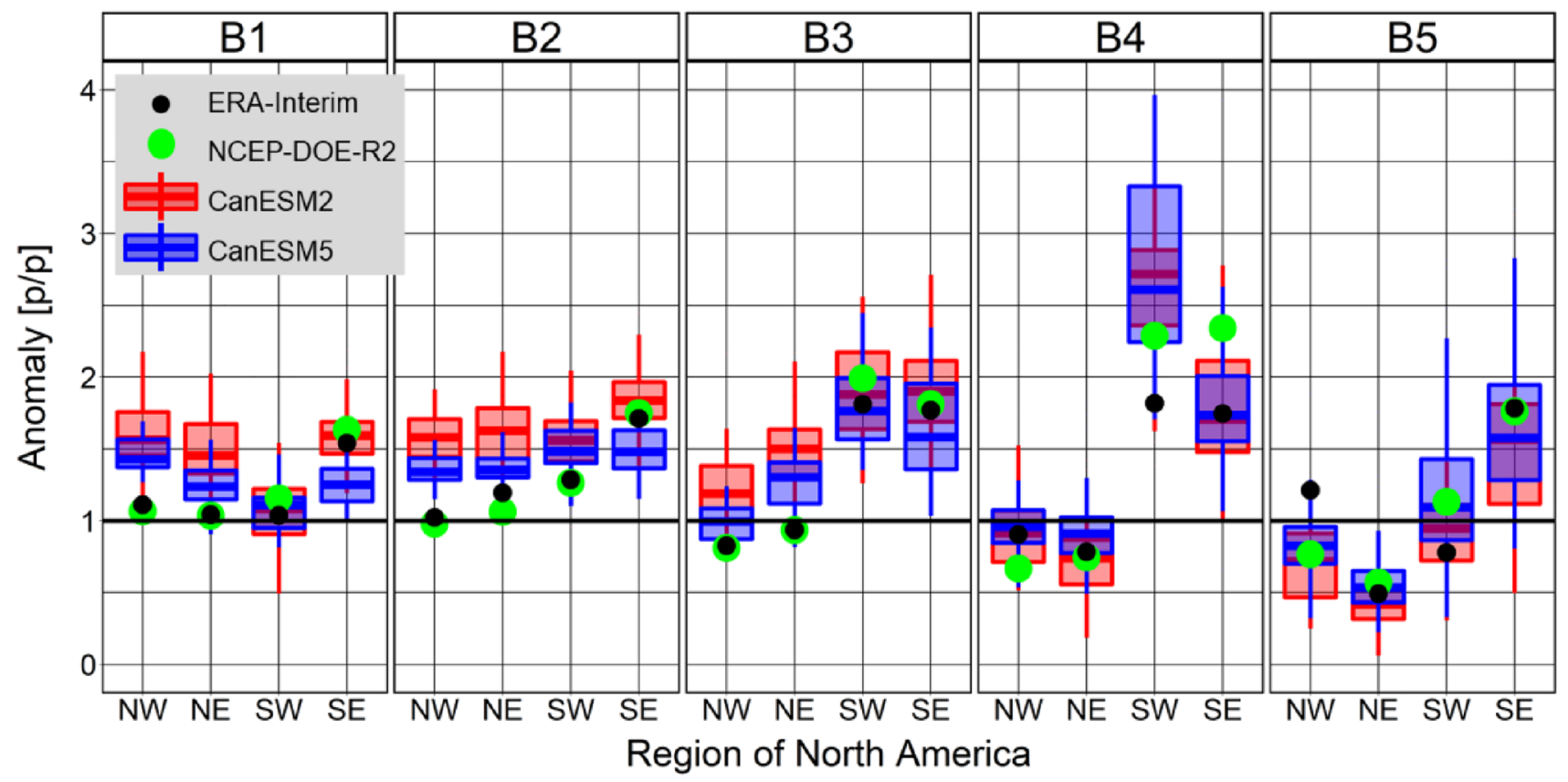

(b) Percentage of cold spell events coincident with blocking days

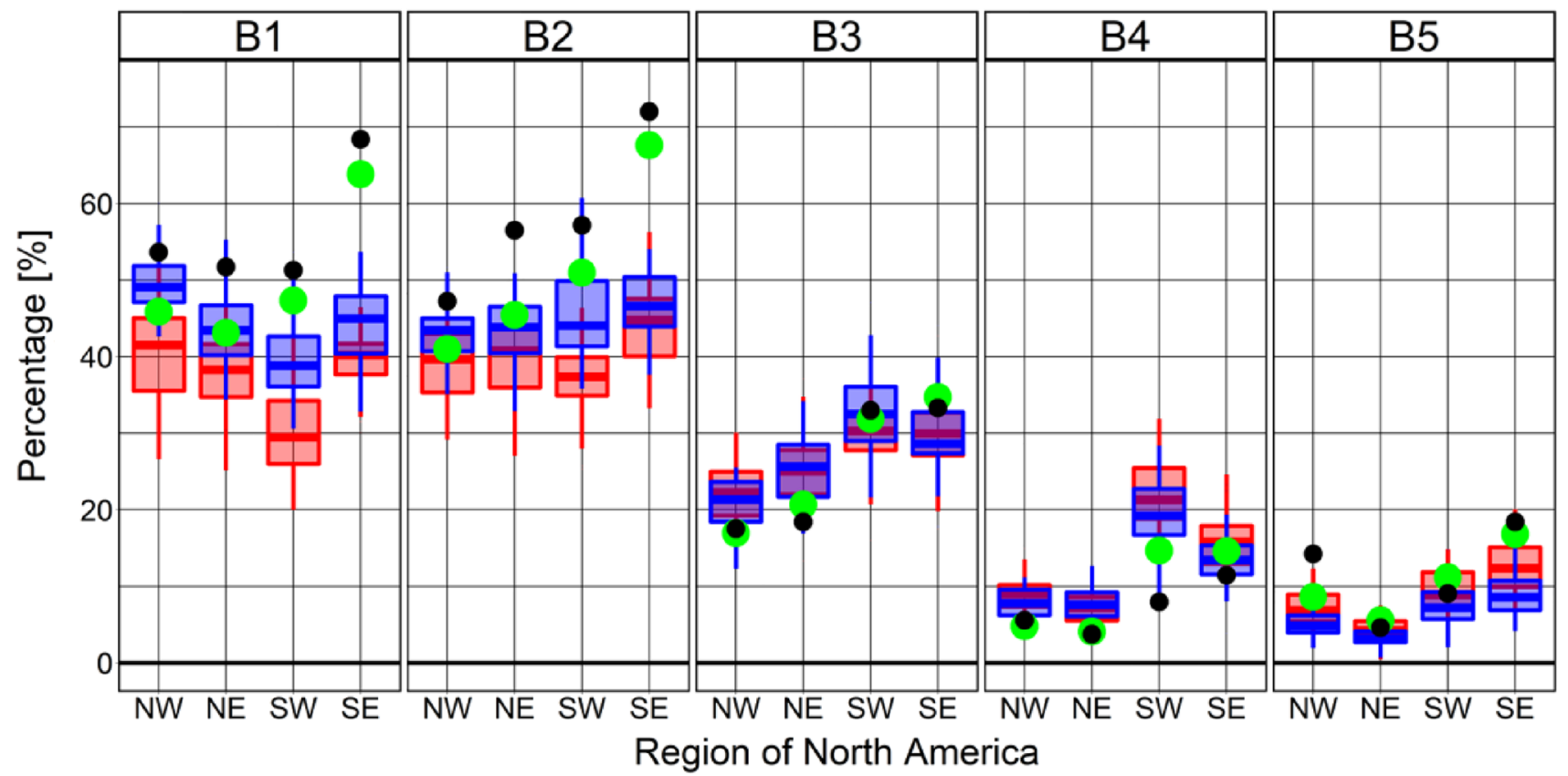

Fig. 5 Regional averages of a cold spell frequency anomaly and $\mathbf{b}$ percentage of cold spell events coinsident with blocking days in the five regions (B1-B5) for ERA-Interim (black dots), NCEP-DOE-

and CanESM5. Note that a blocking could occur in more than one region simultaneously among the five regions B1-B5. Based on NCEP-DOE-R2, 58\%, 58\%, 64\%, and $80 \%$ of winter cold spell events over northwest, northeast,
R2 (green dots), CanESM2 ensemble (red box-plot), and CanESM5 ensemble (blue box-plot) on the four assessment regions of North America (NW, NE, SW, and SE) for the 1981-2010 period

southwest, and southeast North America are coincident (i.e., occurring together in time) with any blocking day occurring anywhere within the five regions between $150^{\circ} \mathrm{E}$ and $60^{\circ}$ W (not shown). More specifically, Fig. 5b presents regional 
averages of the two reanalyses and two ensembles over the four regions of North America for the percentages of winter cold spell events coincident in timing with any blocking day in each blocking region (Fig. 1) relative to total number of cold spell events at each grid point over North America. Spatial distributions of this statistic are presented in Fig. 6. On average, 50 and $51 \%$ of winter cold spells across North America in NCEP-DOE-R2, and larger percentages of 63 and $67 \%$ over southeast North America, are coincident with blocking events in the northeastern edge of Russia (B1) and western Alaska (B2), respectively. The percentages of ERAInterim are 5-7\% points higher relative to those of NCEPDOE-R2. The two reanalyses yield smaller percentages (around $26 \%, 8 \%$, and $11 \%$, respectively) of cold spell events over North America connected with blocking events in the western Canada (B3), central Canada (B4), and eastern Canada (B5). This variability of the percentages with respect to the blocking location is generally consistent with the variability of the blocking climatology in winter shown in Fig. 1. However, it is notable that blocking events occurring in the regions B3 to B5 have stronger positive relationships with cold spells over the southern North America (i.e., SW and
SE) shown in Figs. 4 and 5a, despite the low frequency of winter blocking in the three regions. Compared to NCEPDOE-R2, CanESM5 ensemble underestimates, on average by $-13.1 \%$, cold spell events over SW and SE regions that are coincident with blocking occurring in the regions B1 and $\mathrm{B} 2$. This is primarily due to negative biases in blocking frequency in these regions $(-29.0 \%)$ (Fig. 1) rather than the relatively smaller difference in cold spell frequency $(-2.3 \%)$ (Fig. 3). However, CanESM5 ensemble shows better agreement with NCEP-DOE-R2 over NW and NE regions, despite the underestimated blocking frequency, because the stronger blocking-cold spell connection between the blocking regions and northern North America (Fig. 4) offsets the effects of the negative biases of the blocking frequency. Nevertheless, improved ability of CanESM5 to reproduce blocking activities and associated large-scale atmosphere circulations over CanESM2 (Swart et al. 2019) result in better representation by CanESM5 of cold spells coincident with blocking events. However, the two ensembles generally show an agreement with the two reanalyses in the spatial variability of the percentages (Fig. 6).

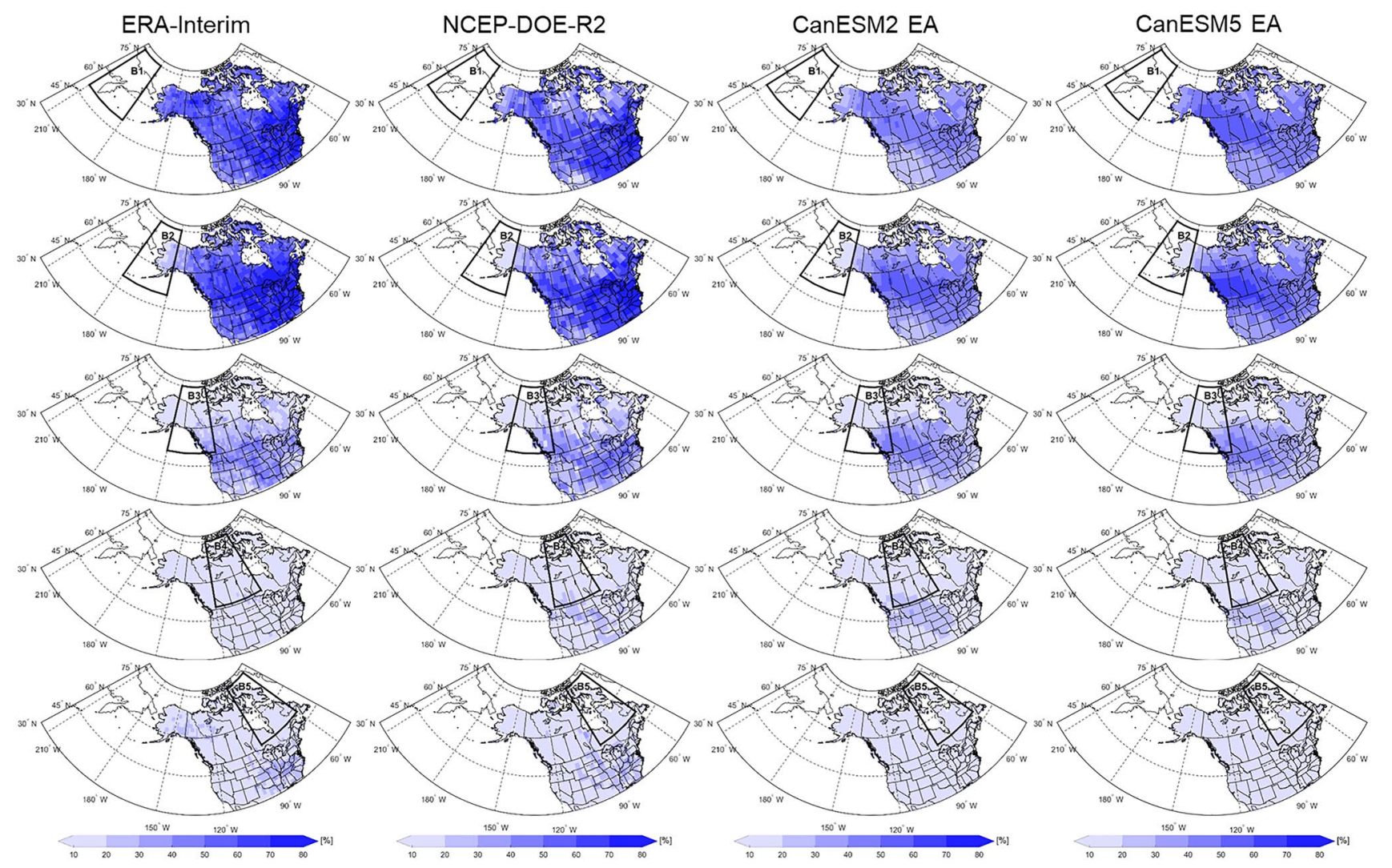

Fig. 6 Percentage of cold spell events coinsident with blocking days in the five blocking regions (B1-B5; black boxes) for ERA-Interim, NCEP-DOE-R2, and ensemble averages (EAs) of CanESM2 and CanESM5 in winter (December-February) for the 1981-2010 period.
Note that the percentage does not include a climatological information at each grid point, unlike the cold spell frequency anomaly presented in Fig. 4 


\subsection{Temperature advection and surface heat flux anomalies on blocking}

The two reanalyses show strong negative temperature advection anomalies at $850 \mathrm{hPa}$ during blocking episodes on the east and south flanks of each blocking region, which are driven by northerly and/or easterly wind anomalies associated with the anomalous anti-cyclonic circulation (Fig. 7). This spatial pattern of negative temperature advection over North America during blocking in winter is in line with the findings over Europe (e.g., Trigo et al. 2004; Sousa et al. 2018). Meanwhile, the two reanalyses reveal positive temperature advection anomalies on the west flank of the blocking regions B3-B5, induced by the anomalous anticyclone related southerly wind anomalies. In addition, the two reanalyses display positive advection anomalies over southwest North America during blocks in regions B3 and B4. CanESM2 and CanESM5 ensembles show a general agreement but some regional-scale disagreements for the temperature advection and wind anomalies with the two reanalyses. The disagreements partly explain the differences in the cold spell frequency anomalies between the two ensembles and the two reanalyses. Specifically, the two ensembles exhibit stronger negative advection anomalies compared to the two reanalyses in western Canada during blocking in the regions $\mathrm{B} 1$ and $\mathrm{B} 2$, which contribute to their overestimation of cold spell frequency anomalies over western Canada. Stronger negative temperature advection could result from colder temperature biases and associated overestimation of sea-ice-covered areas at high-latitudes, as well as positive biases of surface zonal winds at mid-latitudes of CanESM models relative to ERA5 reanalysis (Swart et al. 2019). The two ensembles also have difficulty reproducing the negative temperature advection shown in ERA-Interim over the southeast North America during blocks in regions B1-B4. Particularly, CanESM5 shows larger differences from the reanalyses compared to CanESM2 for temperature advection anomalies over southeast North America during blocking in regions $\mathrm{B} 1$ and $\mathrm{B} 2$. This difference results in under-representation of cold spell frequency anomalies by CanESM5 in those cases. However, the two ensembles and the two reanalyses yield similar negative anomalies of 1000-500 $\mathrm{hPa}$ thickness during blocking in regions B1-B4, indicating that the atmosphere is heavier and colder than average over southeast North America (Fig. 8). This agreement in the geopotential thickness demonstrates the agreement of the
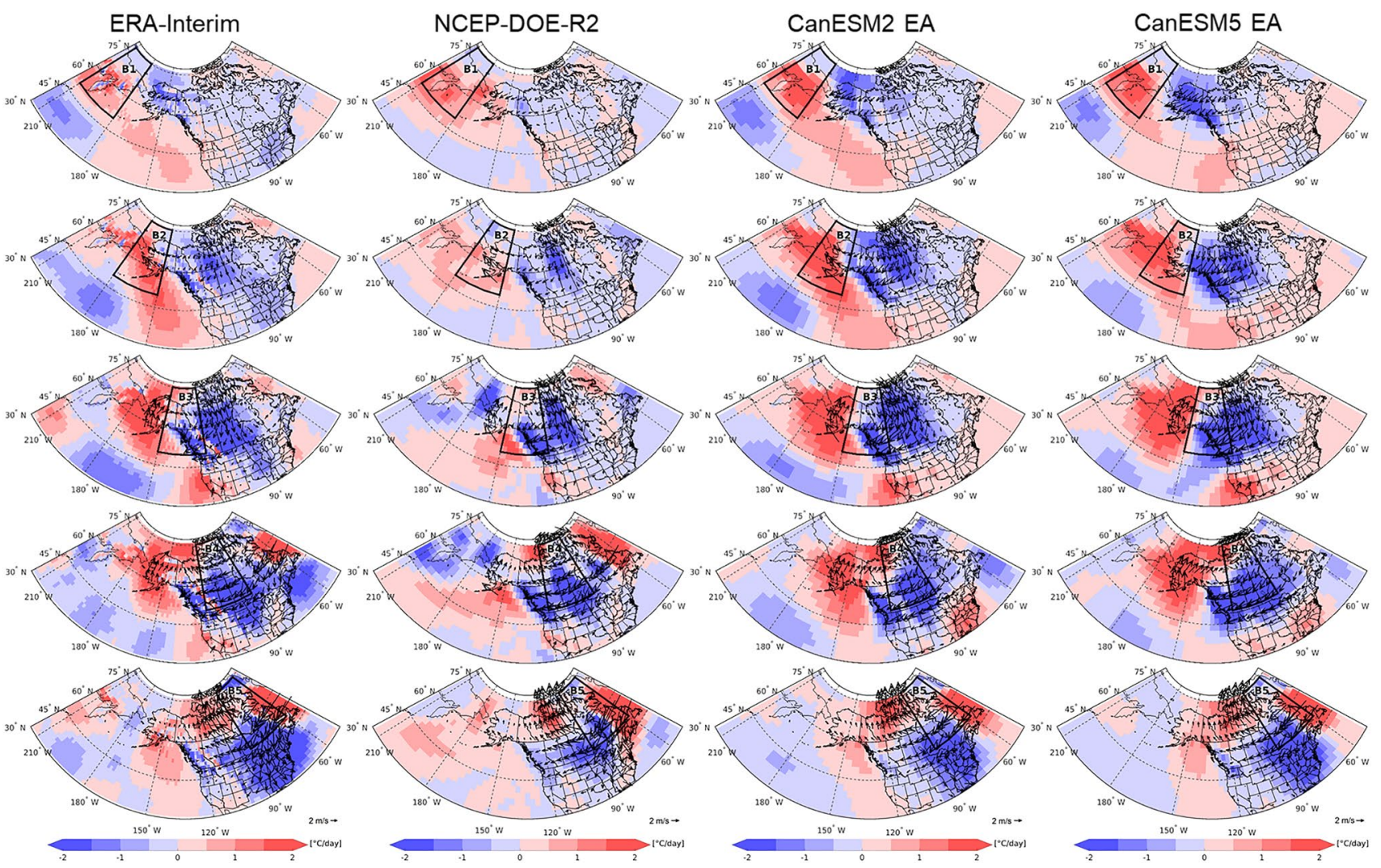

Fig. 7 Mean temperature advection anomaly [unit: ${ }^{\circ} \mathrm{C} / \mathrm{day}$ ] and wind vector anomaly [arrows] at $850 \mathrm{hPa}$ field on blocking days in the five blocking regions (B1-B5; black boxes) for ERA-Interim, NCEP-
DOE-R2, and ensemble averages (EAs) of CanESM2, and CanESM5 in winter (DJF) for the 1981-2010 period 

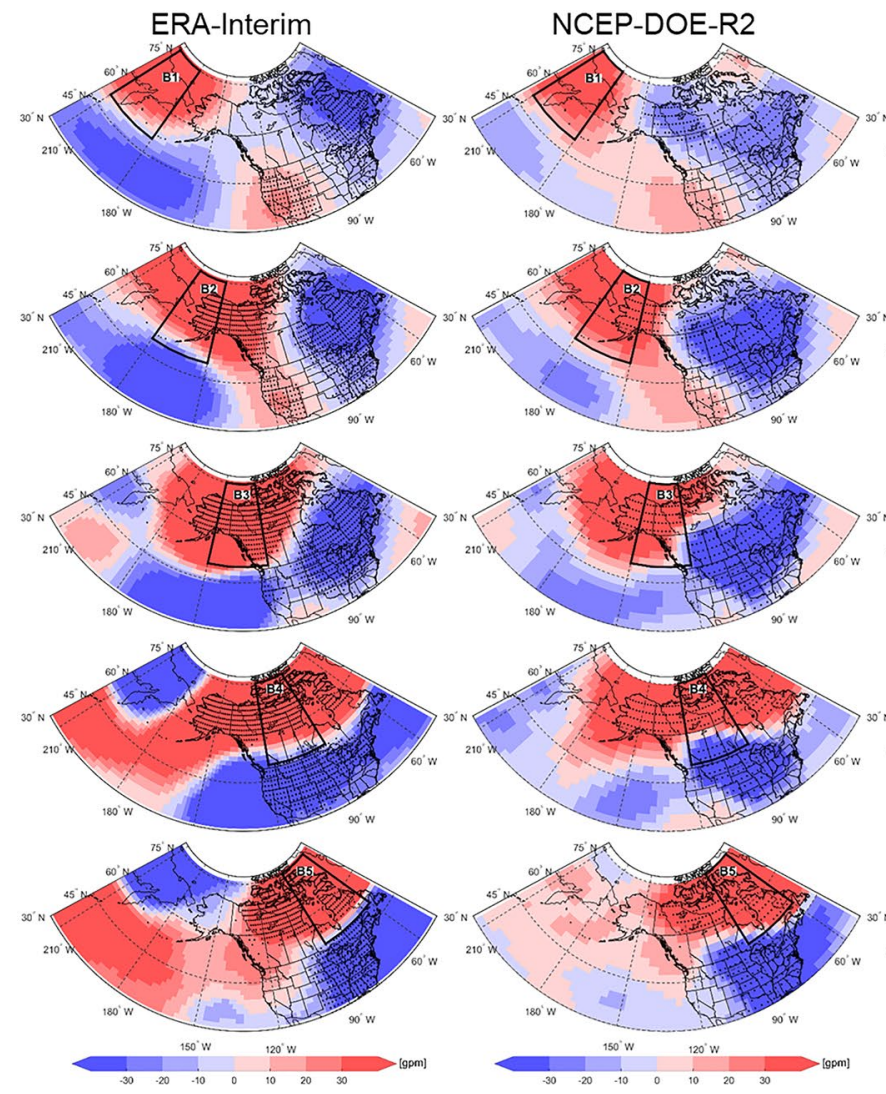

Fig. 8 500-1000 hPa geopotential thickness anomaly [unit: gpm] on blocking days in the five blocking regions (B1-B5; black boxes) for ERA-Interim, NCEP-DOE-R2, and ensemble averages (EAs) of CanESM2, and CanESM5 in winter for the 1981-2010 period. Black dots represent statistical significance at the $10 \%$ significant level

anomalous cold spell occurrence over the southeast North America among the ensembles and reanalyses as described above.

The two reanalyses yield positive anomalies of the net surface heat flux at the diurnal scale in the blocking regions of B2-B5 and their east and west sides (Fig. 9), which contribute to the below-normal cold spell frequency in those regions (Fig. 4). The anti-cyclonic high-pressure of blocking would bring positive surface radiation anomalies with clear-sky conditions, particularly in the core and surrounding areas of the blocking. Moreover, 57 and $50 \%$ of blocking occurring in regions B3 and B4 also covers the western side of blocking in regions B2 and B3, respectively, which partly explains the strong positive anomalies on the western sides of blocking regions B3 and B4 in Figs. 9 and 10. It is notable that the radiative components (Fig. 10) dominate the net surface heat flux (Fig. 9) in the blocking area. In addition to this, Sousa et al. (2018) showed that vertical advection could dominate positive temperature anomalies over the core and surrounding areas of the blocking. This is not investigated in this study as daily vertical winds are unavailable from
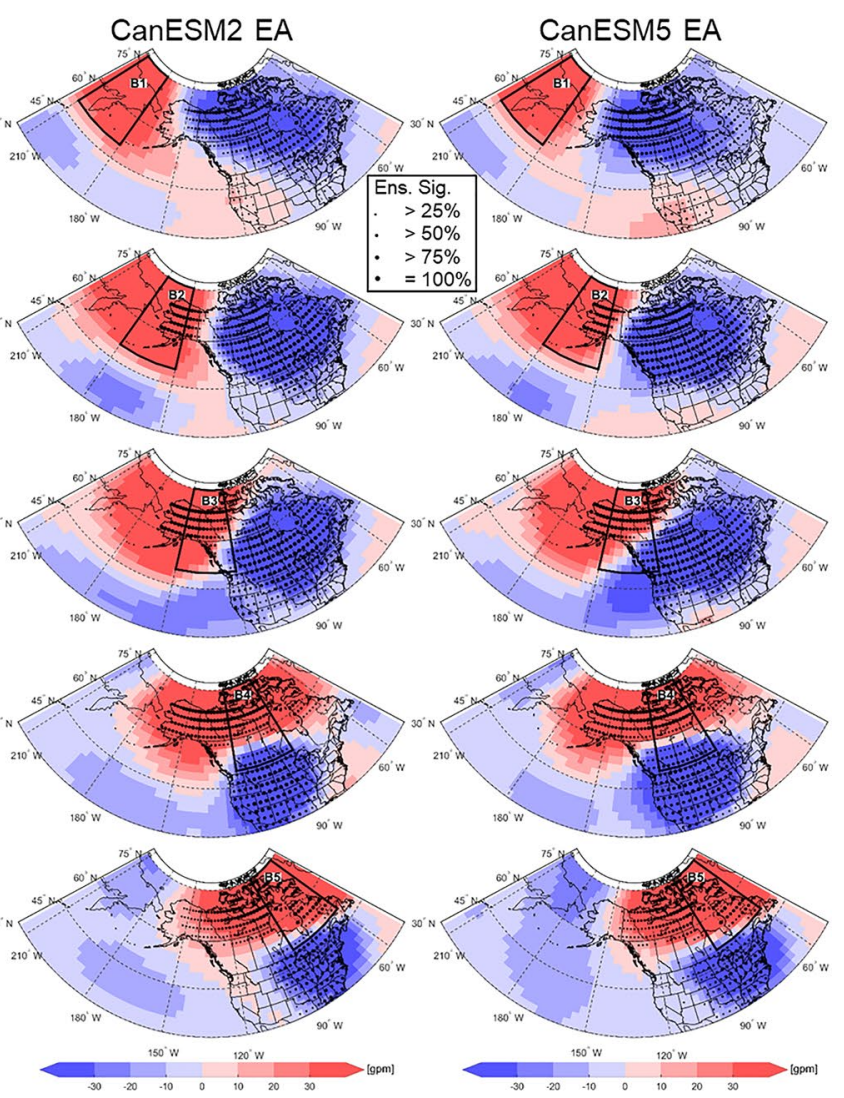

(two-sided). The larger dot size for the CanESM2 and CanESM5 ensembles represents the larger number of ensemble members yield statistical significance (percentages of the number are defined in the legend)

the two ensembles. Meanwhile, the two reanalyses display negative anomalies of the net surface heat flux as well as radiative components over the other land areas of North America. These anomalies are in a spatial agreement with the above-normal cold spell frequency, indicating the positive contribution of surface heat flux anomalies, accompanied by the positive contribution of advection anomalies, is on the anomalous cold spell over North America. CanESM2 and CanESM5 ensembles yield similar spatial distributions with the two reanalyses for the anomalies of the net surface heat flux and radiative components that results in overall agreement among them in the blocking-cold spell linkage. Particularly, the two ensembles and the two reanalyses show negative anomalies over the southeast North America during blocking in regions B1 to B5, which contributes to the overall agreement amongst them for the linkage between blocking and above-normal cold spell frequency in southeast North America. The two ensembles, however, tend to overestimate negative anomalies of the radiative components of net surface heat flux over NW and NE during blocking at B1-B3 (Figs. 9 and 10), which contributes to overestimation 

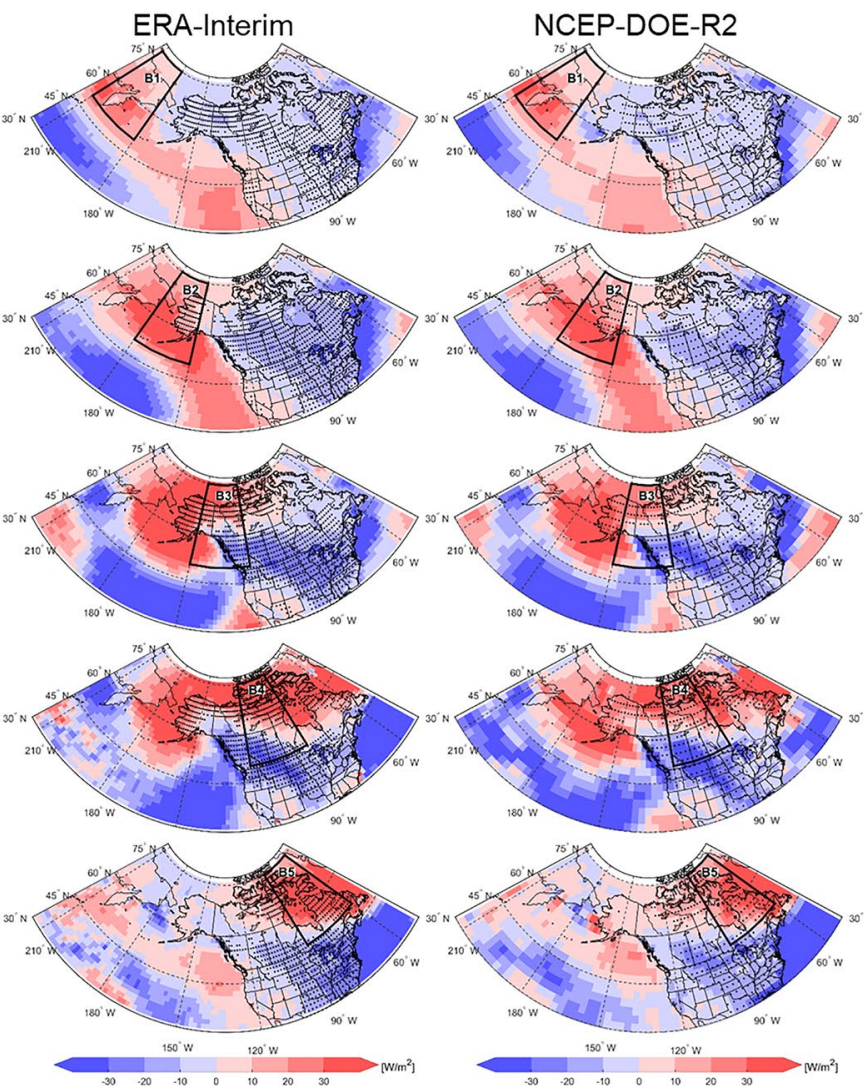

Fig. 9 Net surface heat flux anomaly [unit: $\mathrm{W} / \mathrm{m}^{2}$ ] on blocked days in the five blocking regions (B1-B5; black boxes) for ERA-Interim, NCEP-DOE-R2, and ensemble averages (EAs) of CanESM2, and CanESM5 in winter (DJF) for the 1981-2010 period. Black dots rep-

of the above-normal cold spell frequency in these cases. In addition, the two ensembles show opposite anomalies from ERA-Interim for the net surface heat flux over the western Canada during blocking in the region B5, which also contributes to the opposite anomalies of the cold spell frequency between the two ensembles and ERA-Interim (Fig. 4).

\section{Summary and discussion}

The value of this study lies in elucidating the relationships between blocking and cold extremes over the Pacific-North American sector using global model simulations that have been rarely studied previously. This study also aims to present a better understanding of the relationships by investigating directly related synoptic-scale factors to temperature anomalies, including temperature advection and surface heat fluxes. Moreover, this study attempts for the first time to evaluate the two generations of Canadian Earth System Models (CanESM2 and CanESM5) for their performance and improvement, in terms of reproducing blocking
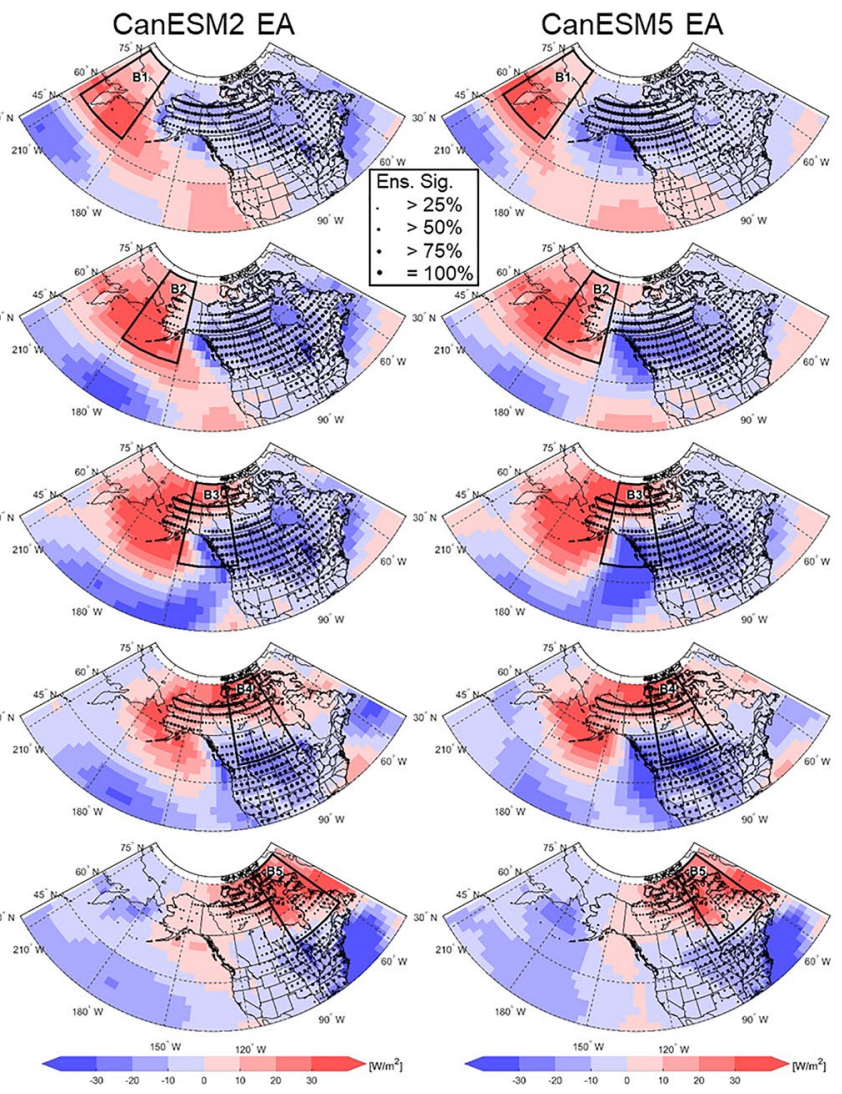

resent statistical significance at the $10 \%$ significant level (two-sided). The larger dot size for the CanESM2 and CanESM5 ensembles represents the larger number of ensemble members yield statistical significance (percentages of the number are defined in the legend)

activities and their influences on cold extremes over the Pacific-North American sector.

The assessment based on ERA-Interim and NCEPDOE-R2 for the 1981-2010 period shows that atmospheric blocking occurs more frequently from northeastern edge of Russia to western Alaska with more than $27 \%$ of blocking days compared to the regions of central and eastern Canada (less than 8\%) during boreal winter. This spatial variability of the blocking climatology over the Pacific-North American sector is consistent with previous findings based on various datasets (e.g., Whan et al. 2016; Woollings et al. 2018). A comparison among the ERA-Interim at $0.75^{\circ}$, upscaled ERA-Interim at $2.5^{\circ}$, and NCEP-DOE-R2 at $2.5^{\circ}$ highlights the resolution dependence of the horizontally resolved blocking detection process that considers spatial extent and temporal persistence (Anstey et al. 2013; Davini and D'Andrea 2016). CanESM5 generally yields better performance to simulate the blocking climatology compared to its predecessor CanESM2, although CanESM2 shows significantly better performance in some cases, such as winter blocking at eastern Canada (B5). Nevertheless, both CanESM2 and CanESM5 show significant underestimation 

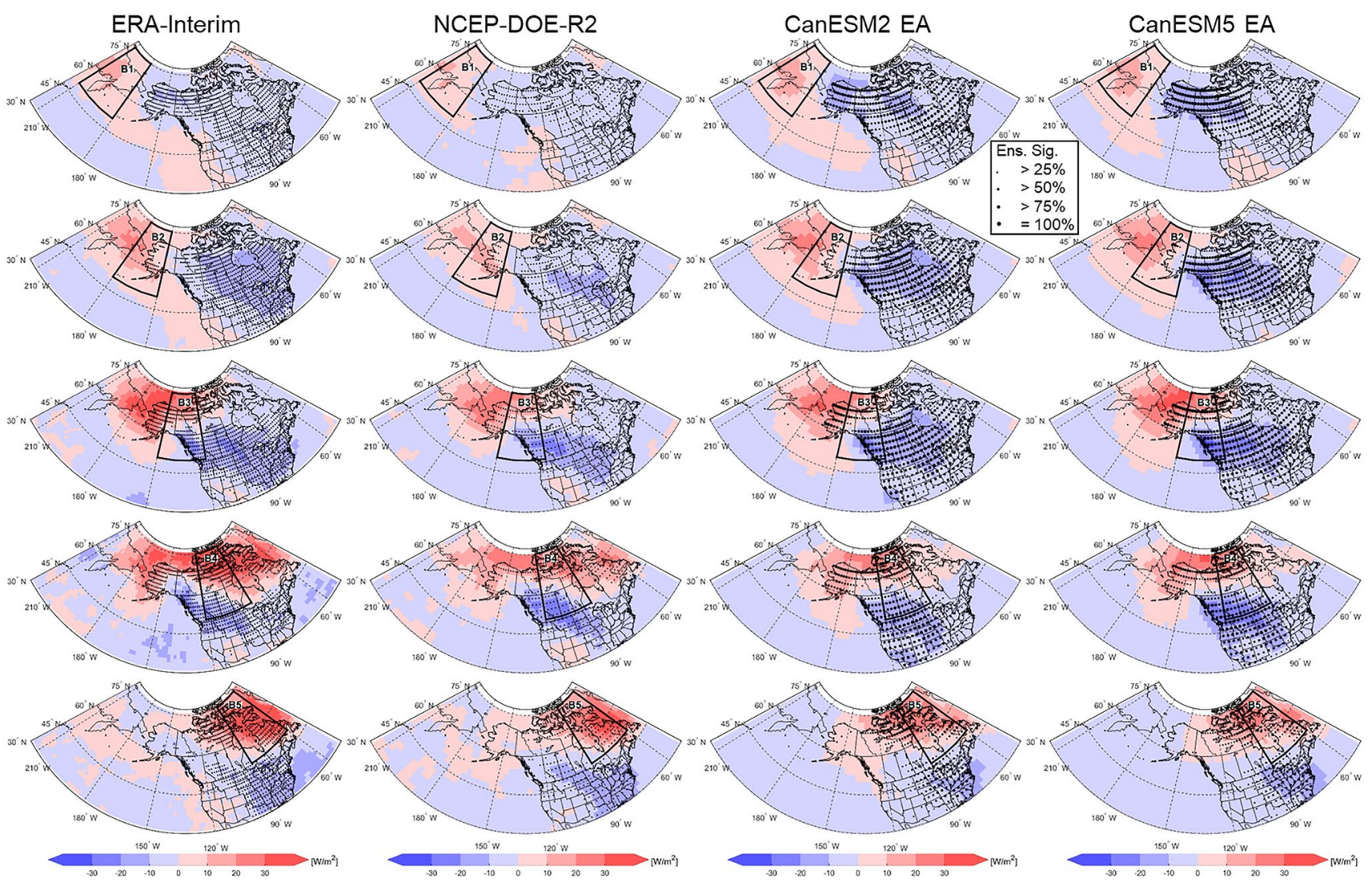

Fig. 10 Anomaly of the radiation components of the net surface heat flux (i.e., shortwave plus longwave downward solar radiations) [unit: $\mathrm{W} / \mathrm{m}^{2}$ ] on blocking days in the five blocking regions (B1-B5; black boxes) for ERA-Interim, NCEP-DOE-R2, and ensemble averages (EAs) of CanESM2, and CanESM5 in winter for the 1981-2010
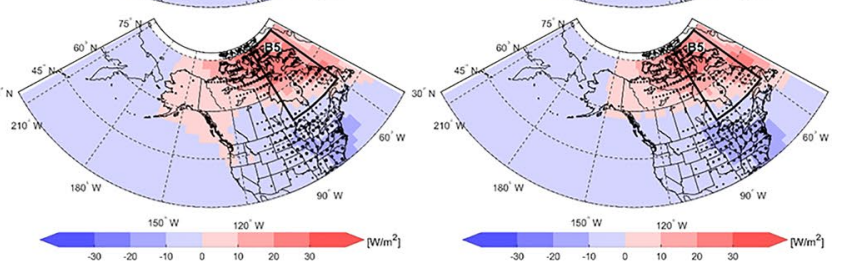

period. Black dots represent statistical significance at the $10 \%$ significant level (two-sided). The larger dot size for the CanESM2 and CanESM5 ensembles represents the larger number of ensemble members yield statistical significance (percentages of the number are defined in the legend)

of winter blocking frequency, particularly over the North Pacific and western Alaska (i.e., on average - 13 days $(-44 \%)$ and -7 days $(-24 \%)$ per winter, respectively, compared to NCEP-DOE-R2).

The two reanalyses show that cold spells coincident with atmosphere blocking are more frequent over southern North America than northern North America. Based on NCEPDOE-R2, 72 and $58 \%$ of winter cold spells over the southern and northern North America are coincident with the blocking. This result is comparable to the finding over the EuroAtlantic sector by Brunner et al. (2018) in which up to 70\% of winter cold spells in central Europe coincide with blocking occurring between Greenland and Scandinavian. CanESM2 and CanESM5 ensembles simulate these connections over the Pacific-North American sector reasonably well. However, when compared to the two reanalyses, CanESM2 and CanESM5 ensembles underestimate, on average by 19.9 and $14.3 \%$ respectively, the frequency of cold spell events over North America that coincide with blocking. This is based on significant under-representation of the blocking frequency of CanESM2 and CanESM5 in regions from the North Pacific to western Alaska (- 47.1 and $-29.0 \%)$ rather than the smaller differences in cold spell frequency (6.6 and $-4.7 \%)$. Relative to unconditional climatological frequencies shown in Fig. 3, the two reanalyses show statistically significant above-normal cold spell frequency at remote locations from blocking events to the eastern and/or southern flanks, and below-normal frequency at the central and western side of the blocking. Therefore, spatial patterns of the cold spell frequency anomaly are highly dependent on the locations of the blocking events. CanESM2 and CanESM5 ensembles reproduce the blockingcold spell linkage, despite their underestimation of blocking frequency over the North Pacific and coincident cold spells over North America. The two reanalyses and the two ensembles display good spatial agreement between negative temperature advection anomaly and above-normal cold spell frequency on the east and/or south flanks of blocking events caused by the northerly and/or easterly wind anomalies. This indicates the cold temperature advection primarily drives cold temperature extremes during blocking episodes (Trigo et al. 2004; Sousa et al. 2018). Meanwhile, the two ensembles reproduce spatial patterns of positive surface heat flux anomaly of the two 
reanalyses in the core and surrounding area of blocking and general negative anomaly in the other parts of North America, which also contribute to the cold spell occurrence. The spatial consistency between positive surface radiation forcing anomalies and below-normal cold spell frequencies from the two reanalyses and the two ensembles is in line with findings by Trigo et al. (2004) and Pfahl and Wernli (2012). In addition, the two reanalyses and the two ensembles show that the negative surface heat flux forcing on the outside of blocking can contribute to develop cold temperature extremes over North America. Similar levels of internal-variability in the blockingcold spell linkage are found in the two ensembles.

CanESM5 shows an improved representation of the winter blocking climatology at the Pacific-North American sector relative to CanESM2, based on overall improvements in simulating large-scale climate patterns (Swart et al. 2019), although it still underestimates the blocking frequency over the North Pacific. Simulations at finer resolution might be needed to further reduce this bias, as shown in Fig. 1 of this study and Anstey et al. (2013) over the Euro-Atlantic sector. Increasing horizontal resolution may also result in an overall improvement in representing the synoptic-scale atmospheric circulation (Cannon 2020) and associated linkages between blocking and cold temperature extremes over the PacificNorth America. This study identifies blocking events using the meridional gradients of $500 \mathrm{hPa}$ geopotential heights; however, this approach has difficulty detecting omega-shaped blocking events that often occur in the Pacific region, and different blocking methods have their own strengths and weaknesses (Woollings et al. 2018). Therefore, a sensitivity assessment based on different blocking detection approaches may be needed. Continued research is also needed to evaluate the representation of connections in global models between blocking and both cold and hot temperature extremes for all seasons, as well as the physical mechanisms behind the connections. Additionally, the impact of blocking events on North American temperature extremes should be evaluated based on future emission scenarios.

Acknowledgements We thank the Canadian Centre for Climate Modelling and Analysis (CCCma) for providing the CanESM2 and CanESM5 ensemble simulations. We also thank two anonymous reviewers for their constructive comments on this manuscript.

Data availability Simulations from the CanESM2 and CanESM5 large ensembles are publicly available via the NCAR Climate Data Gateway Multi-Model Large Ensemble Archive and the Earth System Grid Federation (ESGF) Data Nodes, respectively.

Open Access This article is licensed under a Creative Commons Attribution 4.0 International License, which permits use, sharing, adaptation, distribution and reproduction in any medium or format, as long as you give appropriate credit to the original author(s) and the source, provide a link to the Creative Commons licence, and indicate if changes were made. The images or other third party material in this article are included in the article's Creative Commons licence, unless indicated otherwise in a credit line to the material. If material is not included in the article's Creative Commons licence and your intended use is not permitted by statutory regulation or exceeds the permitted use, you will need to obtain permission directly from the copyright holder. To view a copy of this licence, visit http://creativecommons.org/licenses/by/4.0/.

\section{References}

Afargan H, Kaspi Y (2017) A midwinter minimum in North Atlantic storm track intensity in years of a strong jet. Geophys Res Lett 44(24):12511-12518

Anstey JA, Davini P, Gray LJ, Woollings TJ, Butchart N, Cagnazzo C, Christiansen B, Hardiman SC, Osprey SM, Yang S (2013) Multi-model analysis of Northern Hemisphere winter blocking: model biases and the role of resolution. J Geophys Res Atmos 118:3956-3971

Arora VK, Scinocca JF, Boer GJ, Christian JR, Denman KL, Flato GM, Kharin VV, Lee WG, Merryfield WJ (2011) Carbon emission limits required to satisfy future representative concentration pathways of greenhouse gases. Geophys Res Lett 38:L05805. https://doi. org/10.1029/2010GL046270

Brunner L, Schaller N, Anstey J, Sillmann J, Steiner AK (2018) Dependence of present and future European temperature extremes on the location of atmospheric blocking. Geophys Res Lett 45(12):6311-6320

Buehler T, Raible CC, Stocker TF (2011) The relationship of winter season North Atlantic blocking frequencies to extreme cold or dry spells in the ERA-40. Tellus Ser A 63(2):212-222

Cannon AJ (2020) Reductions in daily continental-scale atmospheric circulation biases between generations of global climate models: CMIP5 to CMIP6. Environ Res Lett 15(6):064006. https://doi.org/ 10.1088/1748-9326/ab7e4f

Davini P, D'Andrea F (2016) Northern Hemisphere atmospheric blocking representation in global climate models: twenty years of improvements? J Clim 29(24):8823-8840

Davini P, D'Andrea F (2020) From CMIP3 to CMIP6: Northern Hemisphere atmospheric blocking simulation in present and future climate. J Clim 33(23):10021-10038

Dee DP et al (2011) The ERA-Interim reanalysis: configuration and performance of the data assimilation system. Q J R Meteorol Soc 137(656):553-597

Efron B, Tibshirani RJ (1994) An introduction to the bootstrap. CRC press, New York

Fischer EM, Schär C (2010) Consistent geographical patterns of changes in high-impact European heatwaves. Nat Geosci 3(6):398-403

Fyfe JC, Derksen C, Mudryk L, Flato GM, Santer BD, Swart NC, Molotch NP, Zhang X, Wan H, Arora VK, Sciocca J, Jiao Y (2017) Large near-term projected snowpack loss over the western United States. Nat Commun 8:14996. https://doi.org/10.1038/ ncomms14996

Grotjahn R et al (2016) North American extreme temperature events and related large scale meteorological patterns: a review of statistical methods, dynamics, modeling, and trends. Clim Dyn 46(3):1151-1184

Hersbach $\mathrm{H}$ et al (2020) The ERA5 global reanalysis. Q J R Meteorol Soc 146(730):1999-2049

Kanamitsu M, Ebisuzaki W, Woollen J, Yang SK, Hnilo JJ, Fiorino M, Potter GL (2002) NCEP-DOE AMIP-II reanalysis (R-2). Bull Am Meteorol Soc 83(11):1631-1644

LeComte D (2015) US weather highlights 2014: drought and polar vortex. Weatherwise 68(3):12-19 
Lee DY, Ahn JB (2017) Future change in the frequency and intensity of wintertime North Pacific blocking in CMIP5 models. Int J Climatol 37(5):2765-2781

Lehtonen I, Karpechko AY (2016) Observed and modeled tropospheric cold anomalies associated with sudden stratospheric warmings. J Geophys Res Atmos 121(4):1591-1610

Li Y, Ye P, Pu Z, Feng J, Ma B, Wang J (2017) Historical statistics and future changes in long-duration blocking highs in key regions of Eurasia. Theor Appl Climatol 130(3-4):1195-1207

Lormée $\mathrm{H}$ et al (2013) Effects of the February 2012 cold spell on terrestrial birds wintering in France. Ring Migr 28(2):85-97

Masato G, Woollings T, Hoskins BJ (2014) Structure and impact of atmospheric blocking over the Euro-Atlantic region in present-day and future simulations. Geophys Res Lett 41(3):1051-1058

Nakamura H, Sampe T (2002) Trapping of synoptic-scale disturbances into the North-Pacific subtropical jet core in midwinter. Geophys Res Lett 29(16):8-1-8-4. https://doi.org/10.1029/2002GL015535

Pettenuzzo D, Large WG, Pinardi N (2010) On the corrections of ERA40 surface flux products consistent with the Mediterranean heat and water budgets and the connection between basin surface total heat flux and NAO. J Geophys Res 115:C06022. https://doi.org/ 10.1029/2009JC005631

Pfahl S, Wernli H (2012) Quantifying the relevance of atmospheric blocking for co-located temperature extremes in the Northern Hemisphere on (sub-)daily time scales. Geophys Res Lett 39:L12807. https://doi.org/10.1029/2012GL052261

Planchon O, Quénol H, Irimia L, Patriche C (2015) European cold wave during February 2012 and impacts in wine growing regions of Moldavia (Romania). Theor Appl Climatol 120(3-4):469-478

Roland J, Matter SF (2013) Variability in winter climate and winter extremes reduces population growth of an alpine butterfly. Ecology 94(1):190-199

Sanford T, Frumhoff PC, Luers A, Gulledge J (2014) The climate policy narrative for a dangerously warming world. Nat Clim Change 4:164-166

Scherrer SC, Croci-Maspoli M, Schwierz C, Appenzeller C (2006) Two-dimensional indices of atmospheric blocking and their statistical relationship with winter climate patterns in the Euro-Atlantic region. Int J Climatol 26(2):233-249

Schiemann R et al (2020) Northern Hemisphere blocking simulation in current climate models: evaluating progress from the Climate
Model Intercomparison Project Phase 5 to 6 and sensitivity to resolution. Weather Clim Dyn 1(1):277-292

Schwierz C, Croci-Maspoli M, Davies HC (2004) Prespicacious indicators of atmospheric blocking. Geophys Res Lett 31:L06125. https://doi.org/10.1029/2003GL019341

Sheridan SC, Allen MJ (2015) Changes in the frequency and intensity of extreme temperature events and human health concerns. Curr Clim Change Rep 1(3):155-162

Sillmann J, Croci-Maspoli M, Kallache M, Katz RW (2011) Extreme cold winter temperatures in Europe under the Influence of North Atlantic atmospheric blocking. J Clim 24:5899-5913

Sousa PM, Trigo RM, Barriopedro D, Soares PM, Santos JA (2018) European temperature responses to blocking and ridge regional patterns. Clim Dyn 50(1-2):457-477

Swart NC et al (2019) The Canadian Earth System Model version 5 (CanESM5. 0.3). Geosci Model Dev 12(11):4823-4873

Tibaldi S, Molteni F (1990) On the operational predictability of blocking. Tellus Ser A 42:343-365

Trigo RM, Trigo IF, DaCamara CC, Osborn TJ (2004) Climate impact of the European winter blocking episodes from the NCEP/NCAR reanalyses. Clim Dyn 23:17-28

Whan K, Zwiers F, Sillmann J (2016) The influence of atmospheric blocking on extreme winter minimum temperatures in North America. J Clim 29(12):4361-4381

WMO (2012) Cold spell in Europe and Asia in late winter 2011/2012. https://ane4bf-datap1.s3-eu-west-1.amazonaws.com/wmocms/ s3fs-public/news/related_docs/dwd_2012_report.pdf. Accessed 28 Oct 2020

Woollings T, Barriopedro D, Methven J, Son SW, Martius O, Harvey B, Sillmann J, Lupo AR, Seneviratne S (2018) Blocking and its response to climate change. Curr Clim Change Rep 4(3):287-300

Yu B, Lin H, Kharin VV, Wang XL (2020) Interannual variability of North American winter temperature extremes and its associated circulation anomalies in observations and CMIP5 simulations. J Clim 33(3):847-865

Publisher's Note Springer Nature remains neutral with regard to jurisdictional claims in published maps and institutional affiliations. 